\section{Descrição do Alótipo (Macho) de Triatoma guazu Lent \& Wygodzinsky, 1979 Proveniente do Estado do Mato Grosso, Brasil (Hemiptera, Reduviidae)}

\section{Herman Lent, José Jurberg*, Cleber Galvão*/+}

Centro de Ciências Biológicas, Universidade Santa Úrsula, Rua Jornalista Orlando Dantas 59, 22231-010

Rio de Janeiro, RJ, Brasil *Laboratório Nacional e Internacional de Referência em Taxonomia de Triatomíneos, Departamento de Entomologia, Instituto Oswaldo Cruz, Av. Brasil 4365, 21045-900 Rio de Janeiro, RJ, Brasil

Description of the Allotype (Male) of Triatoma guazu Lent \& Wygodzinsky, 1979 from the State of Mato Grosso, Brazil (Hemiptera, Reduviidae) - The authors decribe the allotype of Triatoma guazu Lent \& Wygodzinsky, 1979 and make a morphological analysis, specially in the male external genitalia of samples recently found in Mato Grosso, Brasil, after the original description based on single specimen female from Paraguay.

Key words: Triatominae - Triatoma guazu - Chagas' disease

Esta espécie não foi mais encontrada após a descrição de seu único espécime, o holótipo fêmea feita por Lent e Wygodzinsky (1979 Bull Am Mus Nat Hist 163: 123-520). Da proveniência constava o país de origem (Paraguai). Por ser um dos maiores representantes do gênero Triatoma recebeu o nome específico guazu, que na língua guarani significa grande. Em 1994 foram coletados alguns espécimes dentro de domicílios na localidade de Barra do Garça, MT, Brasil. No presente trabalho estamos acrescentando alguns outros caracteres dos machos, além da descrição da sua genitália externa.

Com auxílio do CNPq, convênio BIRD/FNS/FIOCRUZ $\mathrm{n} \mathrm{o}$ 027/93 e The Commission of the European Communities STD-TS3 CT 920092

${ }^{+}$Contato. Fax: 55-221-290.9339

Recebido em 11 de setembro de 1995

Aceito em 17 de novembro de 1995

\section{DESCRIÇÃO}

Comprimento: 29-30mm (2 fêmeas), 26mm (2 machos)

Largura do pronoto: $6 \mathrm{~mm}$ (fêmeas), $6 \mathrm{~mm}$ (machos); largura do abdome: $10 \mathrm{~mm}$ (fêmeas), $8-9 \mathrm{~mm}$ (machos).

Colorido geral preto, com manchas amarelas nos lados do pescoço, no cório dos hemélitros em dois pontos e em faixas do conexivo. Muito pouco piloso com pequenas cerdas esparsas; tegumento polido principalmente na face ventral do abdome.

Cabeça preta, com pequenos grânulos, estreita e alongada, cerca de três vezes mais longa do que larga e mais longa que o pronoto (igual ao comprimento do pronoto mais a metade do escutelo). Região anteocular cerca de quatro vezes mais longa que a pós-ocular; a anteocular tem margens laterais retilíneas, que são levemente curvadas na pós-ocular. Clípeo mais largo na base e genas largas na base e afiladas no ápice ultrapassando nitidamente o ápice do clípeo. Jugas bem pronunciadas e situadas ao nível dos tubérculos anteníferos.

Olhos grandes ultrapassando nitidamente a face dorsal da cabeça, de perfil apenas atingindo a superfície da face ventral. Distância interocular $(1: 1,25)$ um pouco maior que a largura do olho em vista dorsal. Ocelos salientes situados atrás dos olhos e um pouco afastados destes. Tubérculos anteníferos implantados no meio da região anteocular, laterais e escuros. $1^{\mathrm{o}}$ segmento antenal muito pouco piloso e não atingindo o ápice do clípeo, $2^{\circ}$ segmento antenal bem longo e com pequenas cerdas em toda a sua extensão, $3^{\mathrm{O}}$ segmento mais fino e com cerca de $2 / 3$ do $2^{-}$, $4^{\circ}$ segmento antenal com $2 / 3$ do comprimento do 3 - Proporções entre os segmentos: 1:4,6:3,5:2,3.

Rostro em posição de repouso, bem longo, pois o 3 o segmento atinge o início do sulco proesternal; o $1^{\mathrm{o}}$ segmento é o mais forte e atinge o nível da metade do $1^{\mathrm{O}}$ artículo antenal; $2^{2} \mathrm{o}$ segmento rostral bem longo quase atingindo o bordo posterior do olho, e revestido de fina e curta pilosidade; $3^{\mathrm{o}} \mathrm{seg}$ mento rostral de tamanho aproximadamente igual ao do $1^{\circ}$, só mais fino e pontudo. Proporções: $1: 2,5: 1,1$.

Pescoço alongado, escuro, com pequena mancha amarelada de cada lado.

Pronoto totalmente preto, granuloso no lobo anterior, que é menor que o lobo posterior e mostra 1+1 grânulos discais salientes. Lobo posterior rugoso, bem maior que o anterior; as carenas se iniciam pouco antes do bordo posterior do lobo anterior e terminam no fim do lobo posterior. Húmeros salientes para os lados e arredondados.

Escutelo preto com uma pequena mancha amarelada no centro, relativamente curto, rugoso com $1+1$ tubérculos na base, ápice curto e de ponta rombuda. 
Hemélitros atingindo o ápice do 8 o tergito nos dois sexos e de colorido geral pálido; clavo preto enfumaçado na base e com a metade final amarelo claro. O cório termina em ponta ao nível da $4^{\mathrm{a}}$ mancha negra do conexivo, tem manchas amarelas em todas as células, totalmente na célula cubital (entre as nervuras $\mathrm{Cu}$ e $\mathrm{R}+\mathrm{M}$ ); membrana enfumaçada com nervuras salientes e pretas.

Patas inteiramente pretas; fêmures anteriores não dilatados, com $1+1$ dentículos subapicais nos $1^{\mathrm{O}}$ e $2^{\underline{\mathrm{o}}}$ pares; as tíbias do $1^{\underline{\mathrm{O}}}$ e $2^{\underline{\mathrm{O}}}$ pares de patas dos machos apresentam fossetas esponjosas terminais, nas fêmeas ausentes.

Abdome também totalmente preto na face ventral, largo e mostrando parte dos urotergitos nos limites com o conexivo, este é largo com manchas pretas e amarelas, as manchas amarelas ficam no centro de cada segmento do conexivo e as pretas ocupam o espaço restante e cobrem o sulco intersegmentar. Ficam bem visíveis no conexivo, quer dorsal, quer ventralmente, $6+6$ manchas pretas e 6+6 manchas amarelas, as pretas de forma quadrangular e as amarelas de bordo arredondado ao atingir o nível do abdome. Suturas intersegmentares negras. Extremidade abdominal da fêmea

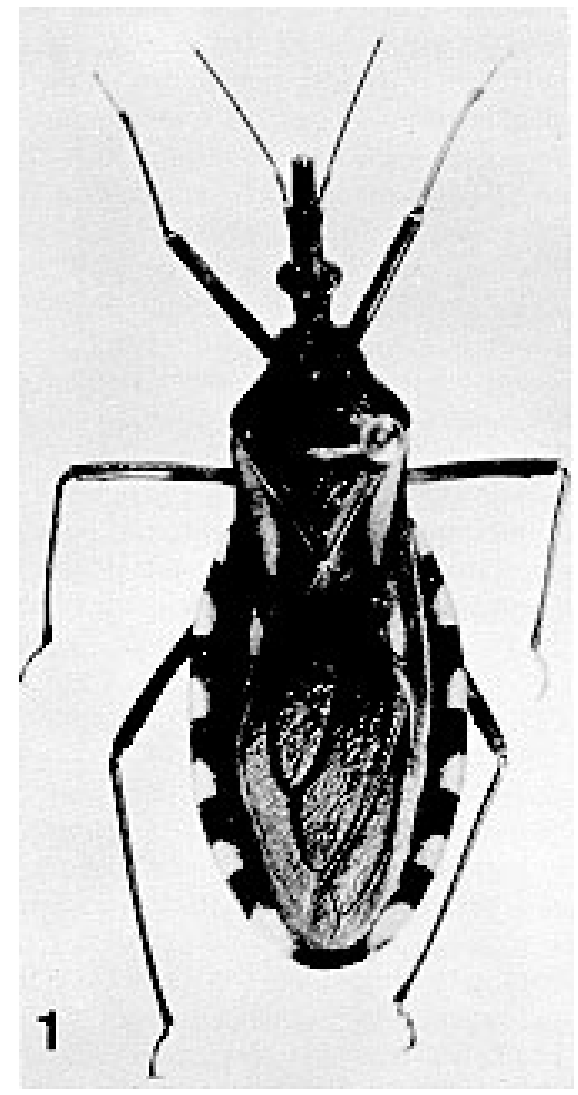

Fig.1: Triatoma guazu Lent \& Wygodzinsky, 1979 - macho (alótipo). romba, a do macho arredondada (Fig.1).

A genitália externa do macho é constituída por um falo e por 1+1 parâmeros homólogos localizados no 9o segmento ou pigóforo, o falo internamente e os parâmeros articulados projetam-se para fora do pigóforo no ato da cópula.

Parâmeros (Pa) cilíndricos, curvados com pelos longos e esparsos situados nas faces externa e interna, com pelos menores próximo ao ápice da face interna. Bordo apical com uma projeção acentuada dirigida para dentro (Fig. $2 \mathrm{~B}$ e C).

Falo (P) constituído de um aparelho articular (Apb) e um edeago (Ae) proporcionais, em repouso o falo fica dobrado com o aparelho articular dorsalmente situado sobre o edeago e este fica com o ápice voltado em direção a cabeça. O aparelho
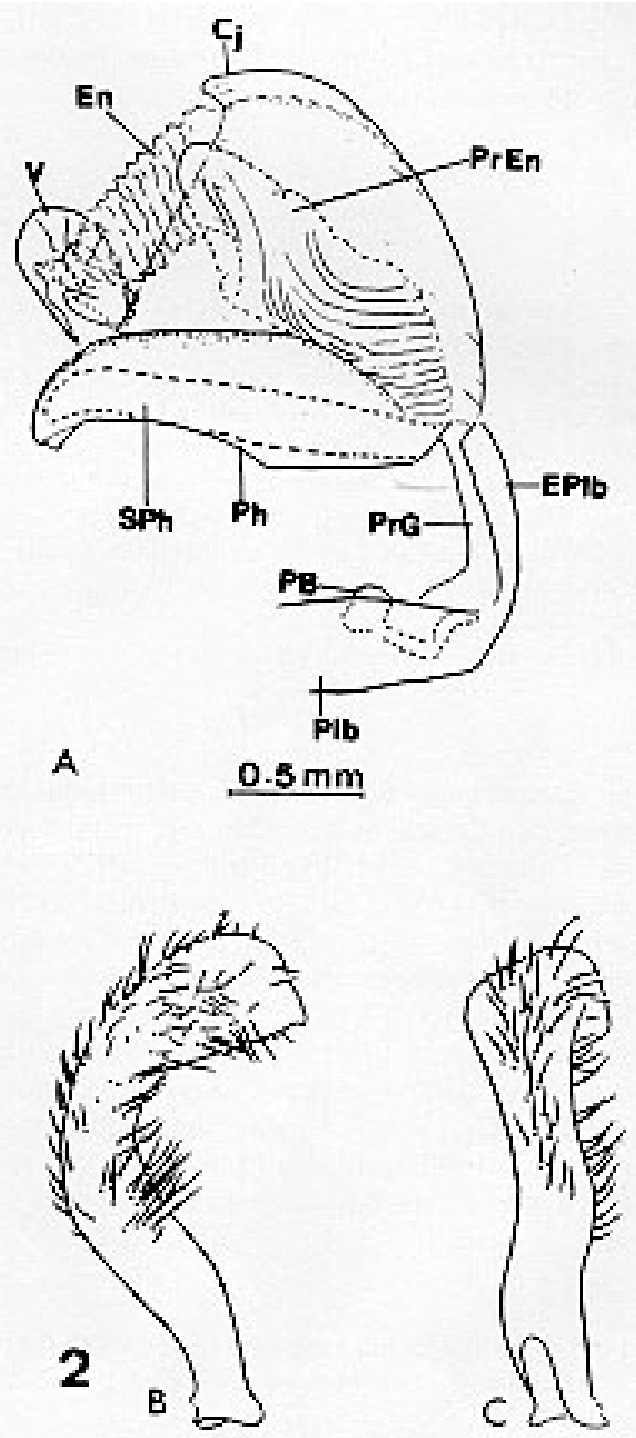

Fig.2: Triatoma guazu Lent \& Wygodzinky,1979 - genitália externa do macho - A: falo - vista lateral; B, C: parâmeros. 
articular tem a forma de $\mathrm{Y}$ invertido, os braços inferiores denominados de placas basais (Plb) se unem na região mediana ao braço ímpar denominado de extensão mediana da placa basal (Eplb) com formato retangular e bordo superior levemente abaulado, na face interna está localizado o processo do gonoporo (PrG) uma estrutura cilíndrica, oca que se prende inferiormente a ponte basal $(\mathrm{PB}) \mathrm{e}$ por onde passa o ducto ejaculatório.

O edeago é um corpo globoso complexo constituído de estruturas rígidas e estruturas elásticas e membranosas. Visto distendido destaca-se na face interna o falosoma $(\mathrm{Ph})$ que é uma placa laminar e ovóide que limita a face inferior e as laterais do edeago, internamente observa-se o suporte do falosoma $(\mathrm{SPh})$ uma estrutura de base cilíndrica e corpo diferenciado em dois braços paralelos que se tocam no ápice, ocupando toda a extensão do falosoma. Na face superior existe uma membrana elástica, estriada longitudinalmente denominada de conjuntiva $(\mathrm{Cj})$ que limita externamente o edeago

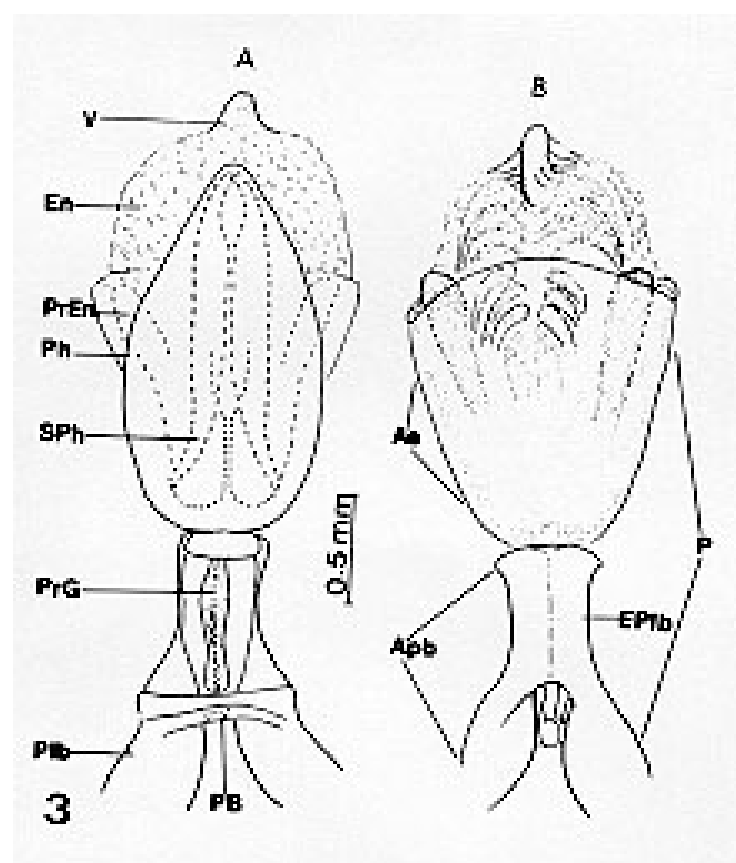

Fig.3: Triatoma guazu Lent \& Wygodzinsky,1979 - genitália externa do macho - falo - A: vista ventral; B: vista dorsal (Ae $=$ edeago, $\mathrm{Apb}=$ aparelho articular, $\mathrm{Cj}=$ conjuntiva, $\mathrm{En}=$ endosoma, $\mathrm{Eplb}=$ extensão mediana da placa basal, $\mathrm{PB}=$ ponte basal, $\mathrm{Ph}=$ falosoma, $\mathrm{Plb}=$ placa basal, $\mathrm{PrEn}=$ processo do endosoma, $\mathrm{PrG}=$ processo do gonoporo, $\mathrm{SPh}=$ suporte do falosoma, $\mathrm{V}$ = vesica).
(Figs. 2A, 3A e B). Internamente está o endosoma (En) membranoso, recoberto de projeções espiniformes, que é a parte eversível do edeago; este possui $1+1$ estruturas mais quitinizadas situadas lateralmente se diferenciando, que são denominadas processos do endosoma (PrEn) estruturas laminares, estriadas e retangulares com o ápice arredondado com pequenos espinhos (Fig. 4C). O ápice do endosoma apresenta uma estrutura ímpar denominada vesica $(\mathrm{V})$ que é uma estrutura ovóide com a face superior elevada no centro de onde partem estrias laterais a face inferior é plana, a vesica limita o gonopóro secundário. (Figs. 4A e B).

Proveniência: Barra do Garça, Mato Grosso, Brasil.

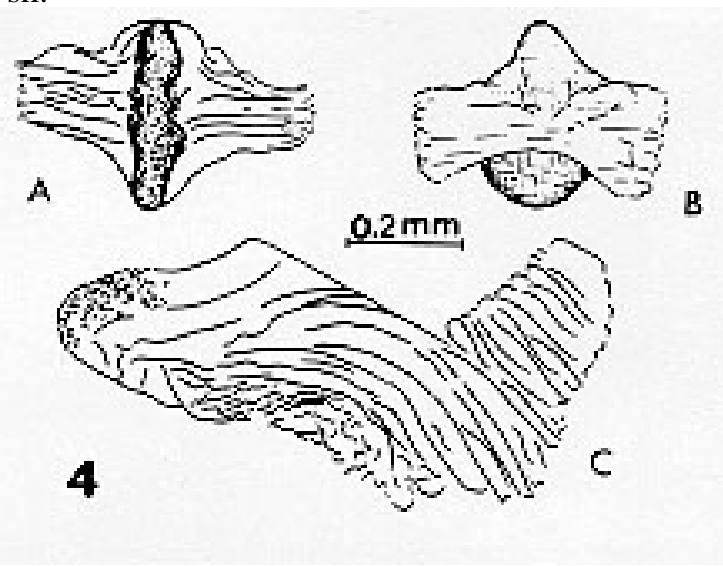

Fig.4: Triatoma guazu Lent \& Wygodzinsky,1979 - genitália externa do macho - A, B: vesica; C: processo do endosoma.

\section{Col.: Sônia Vieira (FNS) 08/94}

Holótipo fêmea depositado no American Museum of Natural History, New York,U.S.A.

Alótipo macho (agora estabelecido) depositado na Coleção Herman Lent do Instituto Oswaldo Cruz, Rio de Janeiro, Brasil (Hem no 2861).

Outros espécimes examinados: macho, Brasil, Mato Grosso, Barra do Garça, S. Vieira col. XI94 (no IOC, Hem. no 2862); fêmea, Brasil, Mato Grosso, Barra do Garça, S. Vieira col. VIII-94 (no IOC Hem. no 2863); fêmea, Brasil, Mato Grosso, Barra do Garça, S. Vieira col. VIII-94 (no IOC Hem. n- 2864).

Agradecimentos: ao Dr. André Avelino de Siqueira Filho e Sônia Vieira Camargo da Silva da Fundação Nacional de Saúde, MT, pelo envio dos espécimes examinados. 
Descrição do Alótipo de Triatoma guazu • Herman Lent et al. 